\title{
Antioxidants Supplementation in Elderly Cardiovascular Patients
}

\author{
Matilde Otero-Losada, Susana Vila, F. Azzato, and José Milei \\ Instituto de Investigaciones Cardiológicas (ININCA), Universidad de Buenos Aires (UBA), \\ Consejo Nacional de Investigaciones Científicas y Técnicas (CONICET), M.T. de Alvear 2270 (C1122AAJ), \\ Buenos Aires, Argentina \\ Correspondence should be addressed to José Milei; ininca@fmed.uba.ar
}

Received 26 August 2013; Revised 5 November 2013; Accepted 8 November 2013

Academic Editor: Sathyasaikumar V. Korrapati

Copyright (C) 2013 Matilde Otero-Losada et al. This is an open access article distributed under the Creative Commons Attribution License, which permits unrestricted use, distribution, and reproduction in any medium, provided the original work is properly cited.

Supplementation with antioxidants and its benefit-risk relationship have been largely discussed in the elderly population. We evaluated whether antioxidants supplementation improved the biochemical profile associated with oxidative metabolism in elderly cardiovascular patients. Patients $(n=112)$ received daily supplementation with $\alpha$-TP $400 \mathrm{mg}$, beta-carotene $40 \mathrm{mg}$, and vitamin C $1000 \mathrm{mg}$ for 2 months (treatment). Plasma concentrations of alpha-tocopherol $(\alpha$-TP), $\beta$-carotene $(\beta \mathrm{C})$, ubiquinol-10 (QH10 ), glutathione, and thiobarbituric acid reactive substances (TBARS) were determined before and after treatment. Response to treatment was dependent on pretreatment $\alpha$-TP and $\beta \mathrm{C}$ levels. Increase in $\alpha$-TP and $\beta \mathrm{C}$ levels was observed only in patients with basal levels $<18 \mu \mathrm{M}$ for $\alpha$-TP $(P<0.01)$ and $<0.30 \mu \mathrm{M}$ for $\beta \mathrm{C}(P<0.02)$. Ubiquinol-10, glutathione, and TBARS were unaffected by treatment: QH-10 $\left(+57 \%, F_{1,110}=3.611, P<0.06\right.$, and N.S. $)$, glutathione $\left(+21 \%, F_{1,110}=2.92, P<0.09\right.$, and N.S.), and TBARS $\left(-29 \%, F_{1,110}=2.26, P<0.14\right.$, and N.S.). Treatment reduced oxidative metabolism: $5.3 \%$ versus $14.6 \%$ basal value $\left(F_{1,110}=9.21\right.$, $P<0.0003)$. Basal TBARS $/ \alpha$-TP ratio was higher in smokers compared to nonsmokers: $0.11 \pm 0.02$ versus $0.06 \pm 0.01\left(F_{32,80}=1.63\right.$, $P<0.04)$. Response to antioxidant supplementation was dependent on basal plasma levels of $\alpha$-TP and $\beta$ C. Smoking status was strongly associated with atherosclerotic cardiovascular disease and high TBARS/ $\alpha$-TP ratio (lipid peroxidation).

\section{Introduction}

Atherosclerotic cardiovascular diseases are a major cause of mortality and morbidity in the general population [1].

Numerous studies have focused on the utility of antioxidant supplementation in the treatment of cardiovascular diseases [2]. Yet, whether antioxidant supplementation has any preventive and/or therapeutic value in cardiovascular pathology is still a matter of debate for evidence is inconclusive [3-9]. Observational studies of vitamins $\mathrm{C}$ and $\mathrm{E}$, the most prevalent natural antioxidant vitamins, suggest that supplemental use of these vitamins may lower the risk for coronary events [10]. High doses of antioxidants may pose risk due to adverse effects [11]. Advertising and marketing encourage consumption of vitamins supplements regardless of proper indication and supplements are ready available onthe-counter for self-medication. The estimated prevalence of dietary-supplement use among US adults was reported to be
$73 \%$ not long ago [9]. In some populations, supplements are consumed to enhance general wellbeing following the advice of friends and magazines [12].

Oxidative stress results from the imbalance between oxidative metabolism and antioxidant activity and is involved in the pathogenesis of atherosclerotic cardiovascular disease (ACVD). Reactive oxygen species (ROS) are by-products of aerobic metabolism that are tightly controlled by antioxidants. Recently the function of ROS in cardiovascular pathology has been reviewed [13].

Antioxidants administration has proved to exert protection against injury in basic research studies [14-17] and imbalance of the antioxidant-oxidant ratio has been reported in experimental models of disease [18-20].

The aim of this study was to evaluate whether supplementation with antioxidants effectively modified the biochemical profile associated with oxidative metabolism in elderly patients undertaking periodical cardiovascular check. 
Vitamin C (ascorbic acid), vitamin E ( $\alpha$-tocopherol), and $\beta$ carotene are considered important antioxidants in humans and were tested in this study [21].

\section{Materials and Methods}

2.1. Design. One-hundred twelve outpatients undertaking periodical cardiovascular checks (51 men, 61 women, 69 \pm 5 years, and living in Buenos Aires city) were selected according to the following criteria. Inclusion criteria are age ( $\geq 65$ years), consumers of a varied diet as recorded in a previous nutritional interview. Exclusion criteria are heavy alcohol drinkers; patients consuming vitamin supplements; vegetarians, vegans, or followers of any restricted diet; patients recovering from an illness, surgery, or infectious process; patients with cerebrovascular events, for example, brain ischemia or stroke; and patients taking medications other than what is indicated (see 2 nd paragraph below).

The patients were assigned to receive daily supplementation with $\alpha$-TP $400 \mathrm{mg}$, beta-carotene $40 \mathrm{mg}$, and vitamin C $1000 \mathrm{mg}$ with dinner for 2 months (end of the study) [22]. This administration schedule was considered appropriate and safe according to our team of nutritionists. A healthy diet was designed by one of the authors of this paper (Susana Vila, medical nutritionist) and the patients signed a written commitment to follow up the diet through the course of the study. At the end of the supplementation treatment data were validated according with a personal nutritional questionnaire completed by the patients on a daily basis.

Four groups of patients were found among those enrolled in this study: "Smoker" smoked more than five cigarettes/day for at least 1 year or after cessation at least 3 months before the beginning of the study; "atherosclerotic cardiovascular disease" (ACVD) had one or more of the following: angina, myocardial infarction, intermittent claudication of lower extremities, previous history of bypass surgery, or angioplasty. "Sedentary" regularly exercised for less than 3 hs/week. "Hypertensive" had diastolic/systolic blood pressure over $140 / 90 \mathrm{mmHg}$ when sitting over three measurements at three consecutive visits. The patients went on taking their respective medication (ACVD: beta-blockers, aspirin, and statins; hypertensive: angiotensin converting enzyme inhibitors, angiotensin receptor blockers, or calcium channel blockers with or without diuretic thiazide) during the study.

The participants signed a written informed consent at the beginning of the study which was conducted in accordance with the Declaration of Helsinki (1964).

2.2. Laboratory Analysis. Plasma concentrations of alphatocopherol $(\alpha$-TP), $\beta$-carotene $(\beta \mathrm{C})$, ubiquinol-10 (QH-10) (HPLC-UV-ED), glutathione (enzymatic assay) [23], and thiobarbituric acid reactive substances (TBARS) (fluorimetry of lipid oxidation products after plasma incubation in the appropriate media, excitation $515 \mathrm{~nm} / 555 \mathrm{~nm}$ emission) [24] were determined before (basal) and after antioxidant supplementation (treatment). Percentage of oxidation was calculated as \%TBARS in incubated samples/\%TBARS in nonincubated samples. HPLC isocratic reverse phase separations were performed using Supelcosil $3 \mu \mathrm{m}$ LC-8DB column $(4.6 \mathrm{~mm}$ $\times 3.3 \mathrm{~cm}$ ) (Supelco, Bellefonte, USA), $\mathrm{LiClO}_{4} 2 \times 10^{4} \mu \mathrm{M}$ in methanol: $\mathrm{H}_{2} \mathrm{O}(99: 1, \mathrm{v} / \mathrm{v})$ as mobile phase $(1 \mathrm{~mL} / \mathrm{min}$ flow rate). EC detection: a BAS LC4C amperometric detector with glassy-carbon working electrode (Bioanalytical Systems Inc., West Lafayette, IN, USA) is set at $+0.6 \mathrm{~V}$ UV detection: a Waters 460 Tunable absorbance detector was used (Millipore Corp., Milford, USA) working at $\lambda=275 \mathrm{~nm}$.

Data was submitted to MANOVA followed by multidimensional scaling with cluster analysis or bivariate correlation analyses (Pearson's product moment correlation coefficient) in order to evaluate the main effects of treatment, data distribution, and the degree of association between variables [25]. Conventionally, the level of statistical significance was set at $P<0.05$ (SPSS 15.0 software, SPSS Inc., Chicago, USA).

\section{Results and Discussion}

The sample of patients comprised smokers (29\%), hypertensives (18\%), sedentary subjects (63\%), and patients with $\operatorname{ACVD}(23 \%)$

The following factors were not related to interindividual variation in basal levels of antioxidants or TBARS: age $\left(F_{4,95}=\right.$ 1.34, $P<0.26$, and N.S. $)$, diabetes $\left(F_{4,95}=1.41, P<0.23\right.$, and N.S.), $\operatorname{ACVD}\left(F_{4,95}=1.45\right.$, and $P<0.22$, N.S.), or sedentarism $\left(F_{4,95}=0.78\right.$, and $P<0.54$, N.S. $)$.

Smoking status was strongly associated with atherosclerotic cardiovascular disease (ACVD): $42 \%$ of smokers had ACVD compared with $16 \%$ of ACVD cases observed in nonsmokers (correlation coefficient $=0.87, P<0.0001$ ). This association was not surprising.

Basal TBARS $/ \alpha$-TP ratio (prooxidant/antioxidant imbalance) was higher in smokers compared to nonsmokers: $0.11 \pm$ 0.02 versus $0.06 \pm 0.01$, respectively $\left(F_{32,80}=1.63, P<0.04\right)$ (Table 1). Alpha-TP, $\beta$ C, glutathione, and ubiquinol-10 levels were dissociated from smoking condition (yet an overall trend to lower antioxidant levels was observed in smokers).

Plasma levels of either $\alpha$-TP or $\beta \mathrm{C}$ were not affected by treatment according to average values of the entire sample of patients. However cluster analysis split the sample into two categories of patients based on pretreatment $\alpha$-TP or $\beta \mathrm{C}$ levels and the plasma levels varied accordingly. Increases in $\alpha$-TP or $\beta C$ levels were observed only in patients with basal levels below either $18 \mu \mathrm{M}$ for $\alpha$-TP $(P<0.01)$ or $0.30 \mu \mathrm{M}$ for $\beta \mathrm{C}(P<0.02)$ (Table 2$)$. The value of $18 \mu \mathrm{M}$ for $\alpha$-tocopherol has been elsewhere considered as the cut point between low and normal $\alpha$-TP plasma concentration ranges [26, 27].

Ubiquinol-10, glutathione, and TBARS levels did not show significant changes following supplementation irrespective of $\alpha$-TP and $\beta \mathrm{C}$ basal levels: QH-10 (57\% increase, $F_{1,110}=3.611, P<0.06$, and N.S.), glutathione (21\% increase, $F_{1,110}=2.92, P<0.09$, and N.S.), TBARS (29\% decrease, $F_{1,110}=2.26, P<0.14$, and N.S.) (Table 2).

Antioxidants supplementation reduced the percentage of oxidation to $5.26 \pm 0.42 \%$ compared with $14.60 \pm 2.19 \%$ found at the beginning of the study $\left(F_{1,110}=9.21, P<0.0003\right)$. Data analysis revealed that the overall decrease in the percentage 
TABLE 1: Plasma levels of antioxidants and oxidative stress' parameters at the beginning of the study.

\begin{tabular}{|c|c|c|c|c|c|}
\hline & Smokers $(n=32)$ & Nonsmokers $(n=80)$ & Hypertensive $(n=20)$ & Sedentary $(n=71)$ & $\operatorname{ACVD}(n=26)$ \\
\hline$\alpha-\mathrm{TP}$ & $19.21 \pm 2.73$ & $22.15 \pm 2.29$ & $21.33 \pm 3.15$ & $21.98 \pm 2.34$ & $20.37 \pm 2.44$ \\
\hline$\beta$-Carotene & $0.29 \pm 0.03$ & $0.34 \pm 0.03$ & $0.32 \pm 0.05$ & $0.33 \pm 0.04$ & $0.27 \pm 0.05$ \\
\hline Ubiquinol-10 & $0.22 \pm 0.04$ & $0.31 \pm 0.05$ & $0.26 \pm 0.04$ & $0.26 \pm 0.03$ & $0.25 \pm 0.07$ \\
\hline Glutathione & $0.64 \pm 0.04$ & $0.73 \pm 0.08$ & $0.68 \pm 0.06$ & $0.69 \pm 0.05$ & $0.67 \pm 0.08$ \\
\hline TBARS & $2.41 \pm 0.63$ & $1.31 \pm 0.37$ & $1.77 \pm 0.36$ & $1.56 \pm 0.29$ & $1.97 \pm 0.31$ \\
\hline TBARS $/ \alpha-\mathrm{TP}$ & $0.13 \pm 0.03^{\#}$ & $0.06 \pm 0.02$ & $0.08 \pm 0.02$ & $0.08 \pm 0.01$ & $0.10 \pm 0.17$ \\
\hline Lipid oxidation (\%) & $18.71 \pm 2.49^{*}$ & $12.61 \pm 2.18$ & $16.62 \pm 1.98$ & $15.31 \pm 2.27$ & $16.15 \pm 2.07$ \\
\hline
\end{tabular}

Plasma concentration is expressed in $\mu \mathrm{M}$ as mean value \pm SEM; $\alpha$-TP: $\alpha$-tocopherol; TBARS: thiobarbituric acid reactive substances.

${ }^{*} P<0.05,{ }^{\#} P<0.04$ versus nonsmokers.

TABLE 2: Effect of antioxidant supplementation on biochemical profile related to oxidative metabolism.

\begin{tabular}{|c|c|c|c|c|}
\hline & \multicolumn{3}{|c|}{ Plasma concentration $(\mu \mathrm{M})$} & \multirow{2}{*}{ Sig. } \\
\hline & Pretreatment & Posttreatment & Ratio (post-/pretreatment) & \\
\hline \multirow{2}{*}{$\alpha-\mathrm{TP}$} & $\geq 18$ & $28.56 \pm 2.60$ & $1.07 \pm 0.09$ & \multirow{2}{*}{$P<0.01$} \\
\hline & $<18$ & $25.76 \pm 2.71$ & $1.61 \pm 0.11$ & \\
\hline \multirow{2}{*}{$\beta C$} & $\geq 0.30$ & $0.39 \pm 0.06$ & $1.05 \pm 0.17$ & \multirow{2}{*}{$P<0.02$} \\
\hline & $<0.30$ & $0.49 \pm 0.17$ & $2.94 \pm 0.36$ & \\
\hline Ubiquinol-10 & $0.27 \pm 0.02$ & $0.42 \pm 0.14$ & $1.57 \pm 0.34$ & NS \\
\hline Glutathione & $0.70 \pm 0.02$ & $0.85 \pm 0.16$ & $1.21 \pm 0.21$ & NS \\
\hline TBARS & $1.52 \pm 0.08$ & $1.07 \pm 0.10$ & $0.71 \pm 0.09$ & NS \\
\hline Lipid oxidation (\%) & $14.60 \pm 2.19$ & $5.26 \pm 0.42$ & $0.36 \pm 0.08$ & $P<0.0003$ \\
\hline
\end{tabular}

$\alpha$-TP: $\alpha$-tocopherol; $\beta$ C: $\beta$-carotene; TBARS: thiobarbituric acid reactive species. Values are expressed as mean \pm SEM.

of lipid oxidation following antioxidant supplementation was mainly attributable to the change observed in patients with basal $\alpha$-TP levels $<18 \mu \mathrm{M}(P<0.0003)$. Only a trend $(P<$ 0.059, N.S.) was found for the association between the change in lipid oxidation and $\beta C$ baseline levels. This observation may drive the conclusion that antioxidant supplementation at the doses administered in the present study, similar to those routinely found in over-the-counter multivitamin supplements, may have some benefits irrespective of the starting $\beta$ C plasma levels.

Overall the subjects did not report any beneficial effects after antioxidants' supplementation except for subjective observations such as "feeling more vital" or a feeling of "general wellbeing"; however, a placebo effect should not be ruled out.

Association of smoking with high oxidant/antioxidant ratio has been reported previously [28, 29].

Only a few of several meta-analyses of the findings of clinical trials using antioxidant supplementation are mentioned below [30-34]. Several cohort studies suggested reduced cardiovascular risk in persons taking vitamin E supplements. However, randomized clinical trials of vitamin E did not show any benefit of vitamin $\mathrm{E}$ supplementation in terms of prevention of coronary heart disease and death [30]. Identical rates of cardiovascular death were found for the placebo and vitamin groups, though a small but significant increase in CVD was found to be associated with $\beta$-carotene supplementation in a meta-analysis that included 7 trials using vitamin $\mathrm{E}$ in $>81,000$ patients and $8 \beta$-carotene trials with $>138,000$ patients [31]. A meta-analysis of 19 clinical trials comprising a total of 135967 participants revealed that supplementation with high doses (16.5 to $2000 \mathrm{IU} / \mathrm{d})$ of vitamin E may cause a slight increase in mortality. A further meta-analysis of the same 19 clinical trials with the inclusion of 10 additional trials (2495 participants, vitamin E doses 136 to $5000 \mathrm{IU} / \mathrm{d}$ ) was later performed and yielded contradictory results. While the former results were confirmed, the results also indicated that the increased mortality odds ratio was not related to supplementation with high doses of vitamin $\mathrm{E}$ in some trials [33].

As a part of a European multicentre project, a study (400 healthy volunteers, 25-45 years) reported that supplementation with alpha-tocopherol and/or carotenoids increased respective serum levels and that no significant side effects (except for carotenodermia) or changes in biochemical or haematological indices had been observed [34].

Oxidative stress has been implicated in pathophysiology of aging and age-associated disease and antioxidants supplementation has become a practice for prevention of atherosclerosis and cardiovascular disease [35]. Clinical studies have not demonstrated a benefit of vitamin $\mathrm{E}$ in the primary and secondary prevention of cardiovascular disease. Vitamin E supplementation was associated with increased mortality, heart failure, and hemorrhagic stroke [1]. The American Heart Association does not support the use of vitamin E supplements to prevent cardiovascular disease and 
recommends the consumption of foods rich in antioxidant vitamins and minerals [1].

Supplementation is usually decided on the assumption that endogenous antioxidants' levels are below the accepted values sometimes underestimating that adverse effects may appear. Supplementation adds an extra burden to the liver and kidneys particularly in elderly patients. A simple laboratory analysis provides information on endogenous antioxidants levels and it may additionally help in reaching a more accurate diagnosis by ruling out (or not) hypothetical7 nutritional deficits.

Two major findings were observed in elderly cardiovascular patients in this study. The increase in plasma levels of $\alpha$-TP or $\beta C$ was dependent on the respective basal levels. Smoking status was strongly associated with atherosclerotic cardiovascular disease and high TBARS/ $\alpha$-TP ratio (lipid peroxidation).

Higher prevalence of ACVD found in smokers agrees with the idea of an oxidative pathogenic substrate in ACVD.

No differences were observed in $\alpha$-TP, $\beta \mathrm{C}$, glutathione, or ubiquinol-10 plasma levels between smokers and nonsmokers in this study in agreement with previous reports [36]. Yet, smoking was associated with higher TBARS/ $\alpha$-TP ratios suggesting an increase in lipid peroxidation relative to antioxidant activity. To our knowledge, this observation was not previously reported. Cigarette smoking is widely accepted to be a major cardiovascular risk factor.

Low plasma levels of antioxidants have been associated with endothelial dysfunction, the first step towards atherosclerosis $[37,38]$ and increased cardiovascular risk. In the present study we considered the relationship between ACVD and plasma levels of antioxidants. Our results do not support the association between ACVD and low serum concentrations of $\alpha$-tocopherol, $\beta$-carotene, glutathione, or ubiquinol-10. The small number of ACVD patients in this study $(n=26)$ may partly account for this discrepancy. It is possible that some of these patients had increased consumption of vegetables and other sources of antioxidants after they suffered a major event of coronary or peripheral vascular disease as well. Other authors arrived to similar results and did not find differences in plasma $\alpha$-TP levels but observed higher $\alpha / \gamma$-tocopherol ratio in patients with coronary heart disease [39].

In this study hypertension, a known risk factor of ACVD, was not associated with differences in plasma antioxidants or TBARS concentrations.

\section{Conclusions}

The effectiveness of antioxidant supplementation to modify plasma biochemistry as a result of changes in oxidative metabolism was dependent on basal endogenous antioxidants levels. Present results suggest that awareness of basal plasma antioxidants levels might be advisable before starting supplementation with antioxidants in elderly cardiovascular patients, a population in which special precautions are recommended. Arguably excess antioxidant levels in tissues may lead to deleterious consequences [40-42]. However, no adverse effects were reported during the course of this study.

\section{Conflict of Interests}

The authors declare that there is no conflict of interests regarding the publication of this paper.

\section{Acknowledgments}

This study was partly supported by Consejo Nacional de Investigaciones Científicas y Técnicas (CONICET) and by funds from ININCA (UBA).

\section{References}

[1] A. Saremi and R. Arora, "Vitamin E and cardiovascular disease," American Journal of Therapeutics, vol. 17, no. 3, pp. e56-e65, 2010.

[2] N. Katsiki and C. Manes, "Is there a role for supplemented antioxidants in the prevention of atherosclerosis?" Clinical Nutrition, vol. 28, no. 1, pp. 3-9, 2009.

[3] K. Prasad, "Vitamin E does not slow the progression of hypercholesterolemic atherosclerosis," International Journal of Angiology, vol. 18, no. 2, pp. 89-95, 2009.

[4] D. P. Vivekananthan, M. S. Penn, S. K. Sapp, A. Hsu, and E. J. Topol, "Use of antioxidant vitamins for the prevention of cardiovascular disease: meta-analysis of randomised trials," The Lancet, vol. 361, pp. 2017-2023, 2003.

[5] E. Lonn, S. Yusuf, B. Hoogwerf et al., "Effects of vitamin E on cardiovascular and microvascular outcomes in high-risk patients with diabetes: results of the HOPE study and MICROHOPE substudy," Diabetes Care, vol. 25, no. 11, pp. 1919-1927, 2002.

[6] H. N. Hodis, W. J. Mack, L. LaBree et al., "Alpha-tocopherol supplementation in healthy individuals reduces low-density lipoprotein oxidation but not atherosclerosis: the vitamin $\mathrm{E}$ atherosclerosis prevention study (VEAPS)," Circulation, vol. 106, no. 12, pp. 1453-1459, 2002.

[7] J. T. Salonen, K. Nyyssönen, R. Salonen et al., "Antioxidant Supplementation in Atherosclerosis Prevention (ASAP) study: a randomized trial of the effect of vitamins $\mathrm{E}$ and $\mathrm{C}$ on 3year progression of carotid atherosclerosis," Journal of Internal Medicine, vol. 248, no. 5, pp. 377-386, 2000.

[8] P. M. Kris-Etherton, A. H. Lichtenstein, B. V. Howard, D. Steinberg, and J. L. Witztum, "Antioxidant vitamin supplements and cardiovascular disease," Circulation, vol. 110, no. 5, pp. 637641, 2004.

[9] R. Sadovsky, N. Collins, A. P. Tighe, S. A. Brunton, and R. Safeer, "Patient use of dietary supplements: a clinician's perspective," Current Medical Research and Opinion, vol. 24, no. 4, pp. 1209$1216,2008$.

[10] G. Riccioni, N. D’Orazio, C. Salvatore, S. Franceschelli, M. Pesce, and L. Speranza, "Carotenoids and vitamins C and E in the prevention of cardiovascular disease," International Journal for Vitamin and Nutrition Research, vol. 82, pp. 15-26, 2012.

[11] B. F. Oliveira, C. A. Veloso, J. A. Nogueira-Machado, and M. Martins Chaves, "High doses of in vitro beta-carotene, alpha-tocopherol and ascorbic acid induce oxidative stress and secretion of IL-6 in peripheral blood mononuclear cells from healthy donors," Current Aging Science, vol. 5, pp. 148-156, 2012. 
[12] M. Kjertakov, R. Hristovski, and M. Racaj, "The use of dietary supplement among soldiers from the macedonian special operations regiment," Journal of Special Operations Medicine, vol. 13, pp. 19-24, 2013.

[13] Y. J. Taverne, A. J. Bogers, D. J. Duncker, and D. Merkus, "Reactive oxygen species and the cardiovascular system," Oxidative Medicine and Cellular Longevity, vol. 2013, Article ID 862423, 15 pages, 2013.

[14] D. A. Lauver, N. M. Kaissarian, and B. R. Lucchesi, "Oral pretreatment with liposomal glutathione attenuates reperfusion injury in rabbit isolated hearts," Journal of Cardiovascular Pharmacology, vol. 61, pp. 233-239, 2013.

[15] F. Radu, R. E. Leggett, C. Schuler, and R. M. Levin, "The effect of antioxidants on the response of the rabbit urinary bladder to in vitro ischemia/reperfusion," Molecular and Cellular Biochemistry, vol. 355, no. 1-2, pp. 65-73, 2011.

[16] S. Llesuy, J. Milei, V. Picone, B. G. Flecha, R. Beigelman, and A. Boveris, "Effect of vitamins A and $\mathrm{E}$ on ischemia-reperfusion damage in rabbit heart," Molecular and Cellular Biochemistry, vol. 145, no. 1, pp. 45-51, 1995.

[17] J. Milei, A. Boveris, and S. Llesuy, "Amelioration of adriamycininduced cardiotoxicity in rabbits by prenylamine and vitamins A and E," American Heart Journal, vol. 111, no. 1, pp. 95-102, 1986.

[18] J. P. Vázquez-Medina, I. Popovich, M. A. Thorwald et al., "Angiotensin receptor-mediated oxidative stress is associated with impaired cardiac redox signaling and mitochondrial function in insulin-resistant rats," American Journal of Physiology: Heart and Circulatory Physiology, vol. 305, pp. H599-H607, 2013.

[19] S. Bryan, B. Baregzay, D. Spicer, P. K. Singal, and N. Khaper, "Redox-inflammatory synergy in the metabolic syndrome," Canadian Journal of Physiology and Pharmacology, vol. 91, pp. 22-30, 2013.

[20] M. E. Otero-Losada, D. R. Grana, A. Müller, G. Ottaviano, G. Ambrosio, and J. Milei, "Lipid profile and plasma antioxidant status in sweet carbonated beverage-induced metabolic syndrome in rat," International Journal of Cardiology, vol. 146, no. 1, pp. 106-109, 2011.

[21] Y. Song, N. R. Cook, C. M. Albert, M. Van Denburgh, and J. E. Manson, "Effects of vitamins $\mathrm{C}$ and $\mathrm{E}$ and $\beta$-carotene on the risk of type 2 diabetes in women at high risk of cardiovascular disease: a randomized controlled trial," American Journal of Clinical Nutrition, vol. 90, no. 2, pp. 429-437, 2009.

[22] M. G. Traber, "The ABCs of vitamin E and $\beta$-carotene absorption," American Journal of Clinical Nutrition, vol. 80, no. 1, pp. 3-4, 2004.

[23] H. Sies and T. P. M. Akerboom, "Glutathione disulfide (GSSG) efflux from cells and tissues," in Methods in Enzymology, B. J. William, Ed., vol. 105, pp. 445-451, Academic Press, New York, NY, USA, 1984.

[24] C. G. Fraga, B. E. Leibovitz, and A. L. Tappel, "Lipid peroxidation measured as thiobarbituric acid-reactive substances in tissue slices. Characterization and comparison with homogenates and microsomes," Free Radical Biology and Medicine, vol. 4, no. 3, pp. 155-161, 1988.

[25] L. S. Meyers, G. Gamst, and A. J. Guarino, Applied Multivariate Research: Design and Interpretation, Sage Publications, Thousand Oaks, Calif, USA, 2006.

[26] F. Carrasquedo, M. Glanc, and C. G. Fraga, "Tissue damage in acute myocardial infarction: selective protection by vitamin E," Free Radical Biology and Medicine, vol. 26, no. 11-12, pp. 15871590, 1999.
[27] P. Weber, A. Bendich, and L. J. Machlin, "Vitamin E and human health: rationale for determining recommended intake levels," Nutrition, vol. 13, no. 5, pp. 450-460, 1997.

[28] P. Suwannalert, P. Boonsiri, T. Khampitak, K. Khampitak, P. Sriboonlue, and P. Yongvanit, "The levels of lycopene, $\alpha$ tocopherol and a marker of oxidative stress in healthy northeast Thai elderly," Asia Pacific Journal of Clinical Nutrition, vol. 16, no. 1, pp. 27-30, 2007.

[29] G. Kelly, "The interaction of cigarette smoking and antioxidants. Part II: alpha-tocopherol," Alternative Medicine Review, vol. 7, no. 6, pp. 500-511, 2002.

[30] S. Ueda and K. Yasunari, "What we learnt from randomized clinical trials and cohort studies of antioxidant vitamin?: focus on Vitamin E and cardiovascular disease," Current Pharmaceutical Biotechnology, vol. 7, no. 2, pp. 69-72, 2006.

[31] S. R. Steinhubl, "Why have antioxidants failed in clinical trials?" American Journal of Cardiology, vol. 101, no. 10, pp. 14D-19D, 2008.

[32] K. Sachidanandam, S. C. Fagan, and A. Ergul, "Oxidative stress and cardiovascular disease: antioxidants and unresolved issues," Cardiovascular Drug Reviews, vol. 23, no. 2, pp. 115-132, 2005.

[33] J. Gerss and W. Köpcke, "The questionable association of vitamin E supplementation and mortality. Iinconsistent results of different meta-analytic approaches," Cell and Molecular Biology, vol. 55, pp. OL1111-OL1120, 2009.

[34] B. Olmedilla, F. Granado, S. Southon et al., "A European multicentre, placebo-controlled supplementation study with $\alpha$ tocopherol, carotene-rich palm oil, lutein or lycopene: analysis of serum responses," Clinical Science, vol. 102, no. 4, pp. 447456, 2002.

[35] H. Otani, "Site-specific antioxidative therapy for prevention of atherosclerosis and cardiovascular disease," Oxidative Medicine and Cellular Longevity, vol. 2013, Article ID 796891, 14 pages, 2013.

[36] K. Miwa and M. Fujita, "Sex difference in effects of smoking on serum vitamin e concentrations in a young population," Journal of Cardiology, vol. 48, no. 4, pp. 201-207, 2006.

[37] L. Franzini, D. Ardigò, S. Valtueña et al., "Food selection based on high total antioxidant capacity improves endothelial function in a low cardiovascular risk population," Nutrition, Metabolism and Cardiovascular Diseases, vol. 22, no. 1, pp. 5057, 2012.

[38] R. Giacco, G. Clemente, D. Cipriano et al., "Effects of the regular consumption of wholemeal wheat foods on cardiovascular risk factors in healthy people," Nutrition, Metabolism and Cardiovascular Diseases, vol. 20, no. 3, pp. 186-194, 2010.

[39] M. Öhrvall, C. Sundlöf, and B. Vessby, "Gamma, but not alpha, tocopherol levels in serum are reduced in coronary heart disease patients," Journal of Internal Medicine, vol. 239, no. 2, pp. 111-117, 1996.

[40] P. P. Singh, A. Chandra, F. Mahdi, A. Roy, and P. Sharma, "Reconvene and reconnect the antioxidant hypothesis in human health and disease," Indian Journal of Clinical Biochemistry, vol. 25, no. 3, pp. 225-243, 2010.

[41] R. Marchioli, G. Levantesi, A. Macchia et al., "Vitamin E increases the risk of developing heart failure after myocardial infarction: results from the GISSI-Prevenzione trial," Journal of Cardiovascular Medicine, vol. 7, no. 5, pp. 347-350, 2006.

[42] Y. Dotan, I. Pinchuk, D. Lichtenberg, and M. Leshno, "Decision analysis supports the paradigm that indiscriminate supplementation of vitamin e does more harm than good," Arteriosclerosis, Thrombosis, and Vascular Biology, vol. 29, no. 9, pp. 1304-1309, 2009. 


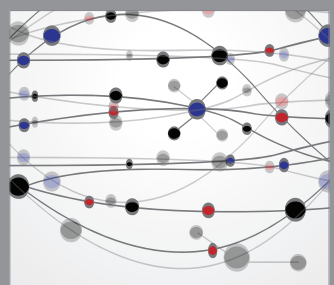

The Scientific World Journal
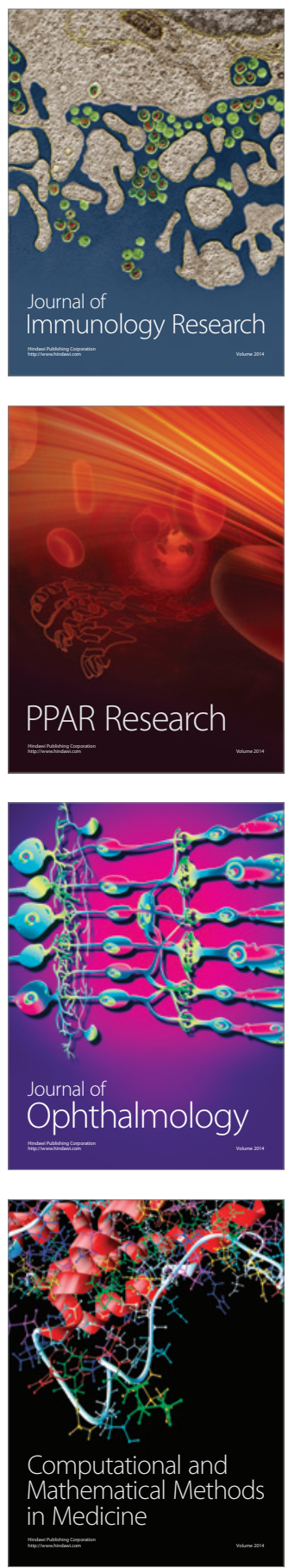

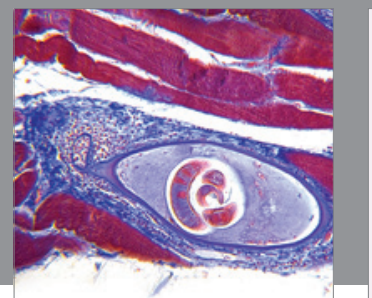

Gastroenterology

Research and Practice
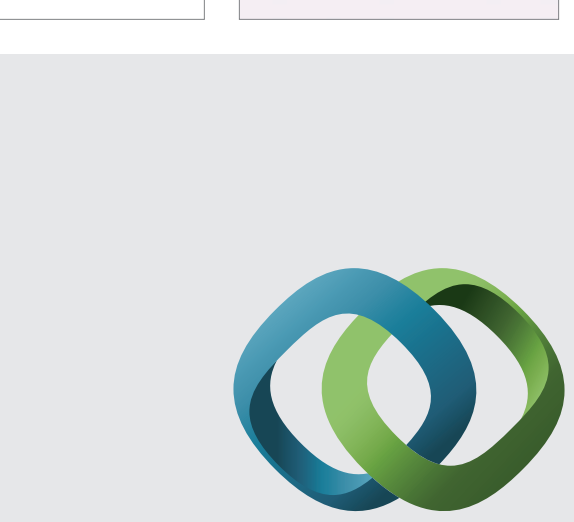

\section{Hindawi}

Submit your manuscripts at

http://www.hindawi.com
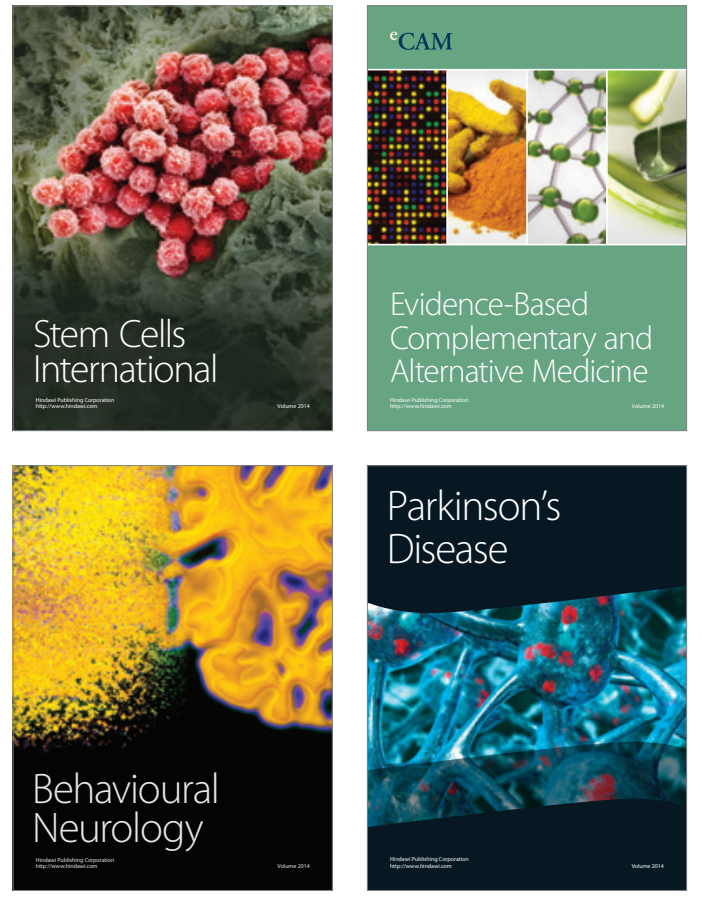
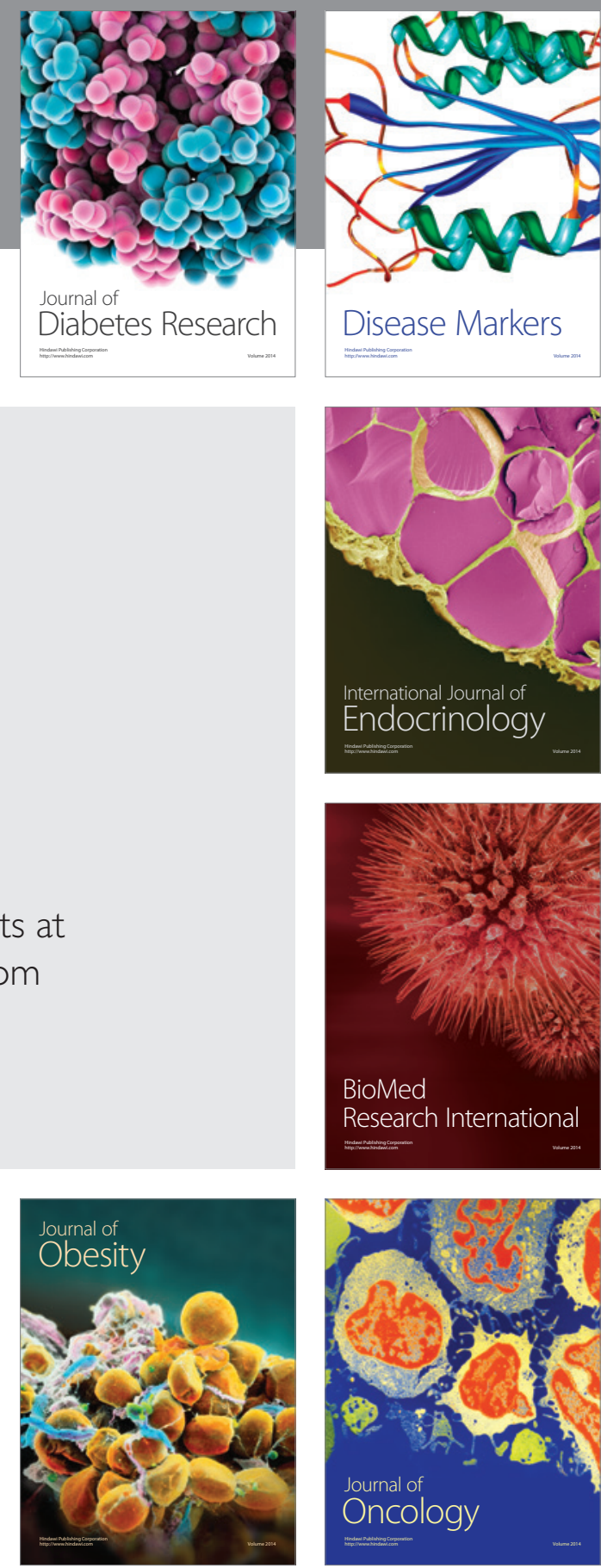

Disease Markers
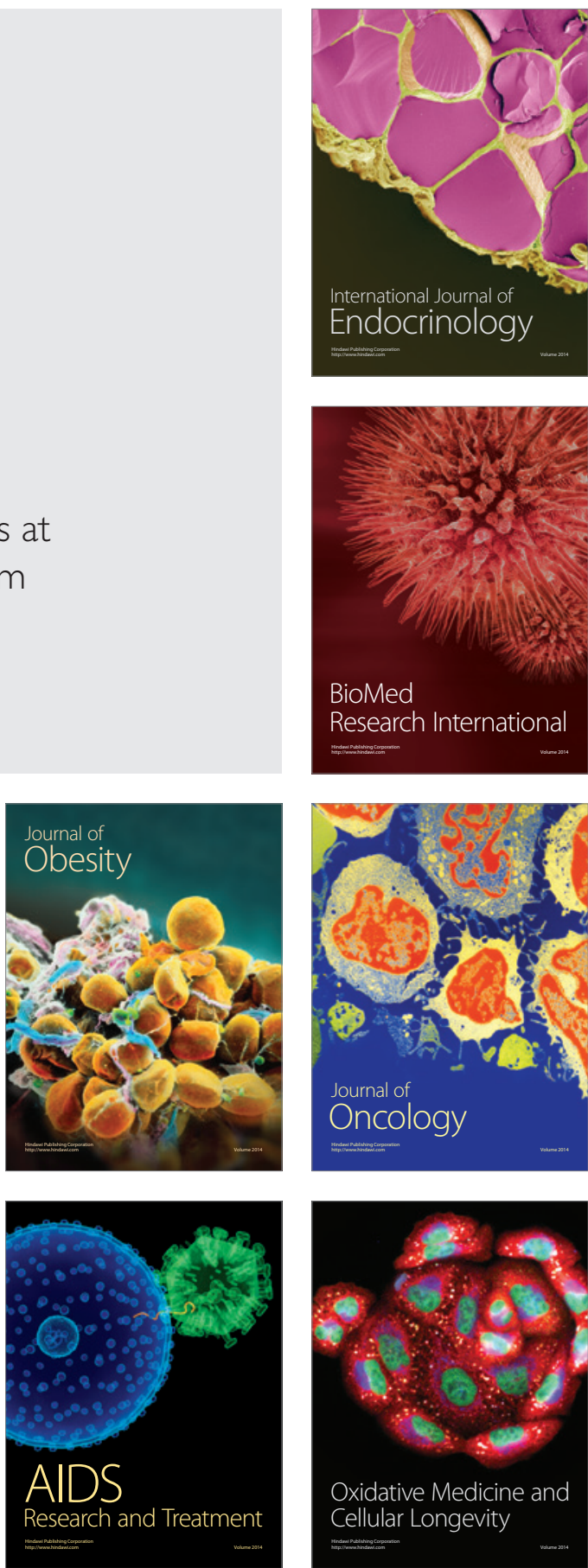